Syntax Literate: Jurnal Ilmiah Indonesia p-ISSN: 2541-0849

e-ISSN: 2548-1398

Vol. 6, No. 1 Januari 2021

\title{
PENGARUH BREATHING EXERCISE TERHADAP PENURUNAN TINGKAT FATIGUE PADA PASIEN HEMODIALISA
}

\section{Maesaroh}

Akademi Keperawatan Buntet Pesantren Cirebon (AKPER BPC) Jawa Barat, Indonesia Email: maesarohskm@gmail.com

\section{Abstract}

Chronic Kidney Disease is a global health problem with a high burden of health costs. In fact, disease can be prevented by making efforts to prevent, control and manage according to standards. To survive, patients with end-stage kidney disease need kidney replacement therapy such as hemodialysis. Despite regular hemodialysis, patients are still affected by symptoms, namely uremic syndrome, with fatigue/fatigue being one of the most common symptoms. This study aims to determine the effect of breathing exercise on decreasing the level of fatigue in hemodialysis patients. This study uses a quasi-experimental method with a pre and post test approach without a control group. Univariate and bivariate analysis. Fatique levels will be compared before and after breathing exercise. Assessment of the level of fatigue using the FACIT scale Number of population 54 respondents, the number of samples that met the inclusion criteria of 16 respondents. The results showed there were significant differences between the levels of fatigue before and after the intervention, meaning that there was an effect of Breathing Exercise on the level of fatigue in hemodialysis patients. Breathing Exercise in many dimensions of fatigue as a non-pharmacological method.

Keywords: breathing exercise; fatigue; hemodialysis

\begin{abstract}
Abstrak
Penyakit ginjal kronis merupakan masalah kesehatan dunia dengan beban biaya kesehatan yang tinggi. Padahal, penyakit ini dapat dicegah dengan melakukan upaya pencegahan, pengendalian dan tatalaksana sesuai standar. Untuk bertahan hidup, pasien dengan penyakit ginjal stadium akhir memerlukan terapi penggantian ginjal seperti hemodialisis. Meskipun hemodialisis reguler, pasien masih dipengaruhi oleh gejala, yaitu sindrom uremik, dengan kelelahan/fatigue menjadi salah satu gejala yang paling umum. Penelitian ini bertujuan untuk mengetahui pengaruh breathing exercise terhadap penurunan tingkat fatique pada pasien hemodialisa. Penelitian ini menggunakan metode kuasi eksperimental dengan pendekatan pre and post test tanpa kelompok kontrol. Tingkat fatique akan dibandingkan sebelum dan sesudah dilakukan breathing exercise. Penilain tingkat fatigue dengan menggunakan skala FACIT Jumlah populasi 54 responden, jumlah sampel yang memenuhi kriteria inklusi 16 responden. Hasil penelitian menunjukkan ada perbedaan signifikan antara tingkat fatique sebelum dan setelah intervensi, berarti ada pengaruh Breathing Exercise terhadap tingkat fatique pada
\end{abstract}


pasien hemodialisa. Breathing Exercise dalam banyak dimensi fatigue digunakan sebagai metode non-farmakologis.

Kata kunci: breathing exercise; fatigue; hemodialisa

\section{Coresponden Author}

Email: maesarohskm@gmail.com

Artikel dengan akses terbuka dibawah lisensi

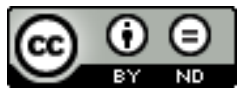

\section{Pendahuluan}

Penyakit ginjal kronis merupakan masalah kesehatan dunia dengan beban biaya kesehatan yang tinggi (UTAMI, 2019). Padahal, penyakit ini dapat dicegah dengan melakukan upaya pencegahan, pengendalian dan tatalaksana sesuai standar. Untuk bertahan hidup, pasien dengan penyakit ginjal stadium akhir memerlukan terapi penggantian ginjal seperti hemodialisis, dialisis peritoneal, atau transplantasi ginjal. Berdasarkan Indonesian Renal Registry (IRR) tahun 2016, sebanyak 98\% penderita gagal ginjal menjalani terapi Hemodialisis dan 2\% menjalani terapi Peritoneal Dialisis (PD) (Kementerian Kesehatan Republik Indonesia, 2018). Hemodialisis adalah metode Dialisis yang paling umum dan tujuan utama dari perawatan ini adalah untuk mencoba dan membuat kehidupan (Parvan, Jabar-Zadeh, Sarbakhsh, Akhtari-Shojai, \& Zarei, 2017). Penyebab penyakit ginjal kronis terbesar adalah nefropati diabetik (52\%), hipertensi (24\%), kelainan bawaan (6\%), asam urat (1\%), penyakit lupus (1\%) dan lainlain (Tuloli, Madania, \& Tuli, 2019) (Manurung \& Sari, 2020). Jumlah pasien hemodialisis baik pasien baru maupun pasien aktif sejak tahun 2007 sampai 2016 mengalami peningkatan, terutama pada tahun 2015 hingga 2016. Berdasarkan usia, pasien hemodialisis terbanyak adalah kelompok usia 45-64 tahun, baik pasien baru maupun pasien aktif (Kompasiana, 2018). Meskipun hemodialisis reguler, pasien masih dipengaruhi oleh gejala, yaitu sindrom uremik, dengan fatigue menjadi salah satu gejala yang paling umum. Setelah sindrom uremik, kapasitas kerja fisik pasien berkurang $50 \%$ dibandingkan dengan orang sehat (Hasmi, 2017). Ada korelasi yang signifikan antara pengurangan aktivitas fisik dan peningkatan depresi atau fatigue. Karena aktivitas menurun, kekuatan individu menurun, yang mengintensifkan depresi dan fatigue.

Secara umum, fatigue telah digambarkan sebagai kelemahan, perasaan fatigue, dan kekurangan energi. fatigue tidak hanya mempengaruhi kehidupan sehari-hari pasien tetapi juga menyebabkan gangguan perawatan diri sehari-hari, status psikologis, dan kualitas hidup. Sekitar 94\% pasien dengan hemodialisis cenderung menjalani lebih banyak sesi dialisis jika itu akan meningkatkan tingkat energi mereka. Namun, beberapa penelitian telah dilakukan dalam hal ini. fatigue, dengan prevalensi $60 \%$ hingga 97\%, telah diusulkan sebagai gejala paling parah yang pernah dilaporkan di antara pasien dengan penyakit ginjal kronis.

Penelitian oleh Jham dkk menunjukkan bahwa pasien dengan penyakit ginjal stadium akhir mengalami tingkat fatigue yang ekstrim (Jhamb, Weisbord, Steel, \& 
Unruh, 2008). Meskipun demikian, itu kurang dikenal atau diobati karena sifat subjektifnya. Metode perawatan untuk fatigue diklasifikasikan menjadi dua kelompok, yaitu farmakologi dan nonfarmakologi. Metode yang pertama melibatkan L-carnitine-, vitamin $\mathrm{C}$, dan resep erythropoietin dan obat-obatan lain untuk mengendalikan anemia. Metode yang terakhir melibatkan latihan, yoga, relaksasi, akupresur, akupunktur, stimulasi listrik, dan dialisis. Olahraga mungkin membantu dalam mengurangi depresi dan fatigue di antara pasien yang menjalani dialisis (Kusniawati, 2018). Latihan dilakukan dengan berbagai cara seperti latihan aerobik, daya tahan, dan ketahanan serta latihan ergometrik kaki dan relaksasi otot progresif. Beberapa penelitian menunjukkan bahwa teknik pencitraan dan relaksasi dapat berhasil digunakan untuk meningkatkan kondisi penyesuaian pasien pada dialisis, salah satu yang akan diteliti adalah tehnik breathing exercise.

Berdasarkan uraian diatas maka penulis tertarik untuk meneliti Pengaruh Breathing Exercise Terhadap Penurunan Tingkat Fatique pada Pasien Hemodialisa di Rumah Sakit Islam Sukapura Jakarta. Tujuan yang ingin dicapai yaitu mengetahui perbedaan signifikan antara tingkat fatique sebelum dan setelah intervensi dan pengaruh Breathing Exercise terhadap tingkat fatique pada pasien hemodialisa di RS Islam Sukapura Jakarta tahun 2019.

\section{Metode Penelitian}

Penelitian ini menggunakan metode kuasi eksperimental dengan pendekatan pre and post test tanpa kelompok kontrol. Tingkat fatique akan dibandingkan sebelum dan sesudah dilakukan breathing exercise.

Tabel 1

Desain penelitian one group pretest-postest (Sugiono, 2010)

\begin{tabular}{ccc}
\hline Pretest & Treatment & Postest \\
\hline $\mathrm{O}_{1}$ & $\mathrm{X}$ & $\mathrm{O}_{2}$ \\
\hline
\end{tabular}

Keterangan:

$\mathrm{O}_{1} \quad$ : Pengukuran tingkat fatique dengan menggunakan FAS sebelum dilakukan tindakkan breathing exercise.

$\mathrm{X} \quad$ : Pemberian Breathing Exercise.

$\mathrm{O}_{2}$ : Pengukuran tingkat fatique dengan menggunakan FAS setelah dilakukan tindakkan breathing exercise.

Tindakkan breathing exercise dilakukan 4 (empat) kali sehari, sekali tindakan selama 15 menit, dilakukan 15 menit di jam pertama, 15 menit jam kedua, 15 menit jam ketiga, 15 menit jam keempat. Hari pertama sebanyak 8 (delapan) responden, hari ke dua sebanyak 8 (delapan) responden, jumlah seluruh responden sebanyak 16 responden, penelitian dilakukan pada bulan Desember 2018, di ruang Hemodialisa Rumah Sakit Islam Sukapura Jakarta. Instrumen menggunakan Skala FACIT, Quesioner, alat tulis: untuk mencatat nama, dan hasil, SOP breathing exercise, SOP pengukuran tingkat 
fatigue. Analisis univariat dilakukan terhadap variabel dari hasil penelitian, pada umumnya analisa ini hanya menghasilkan distribusi frekuensi dan persentase dari tiap variabel (Notoatmodjo, 2012). Dalam penelitian ini distribusi frekuensi responden diantaranya umur, jenis kelamin, riwayat pendidikan serta mendiskripsikan variabelvariabel penelitian secara tersendiri. Analisa bivariat digunakan untuk menganalisis ada tidaknya pengaruh Breathing Exercise terhadap penurunan tingkat fatique dengan menggunakan uji $\mathrm{T}$ dengan SPSS versi 16,0 untuk membandingkan data sebelum dan sesudah diberikan perlakuan.

\section{Hasil dan Pembahasan}

\section{A. Hasil}

\section{Data Univariat}

\section{a. Karakteristik Responden}

Jumlah responden dalam penelitian ini berjumlah 16 orang yang menjalani hemodialisa di Rumah Sakit Islam Sukapura Tahun 2019. Karakteristik responden berdasarkan, jenis kelamin, usia, pekerjaan, tingkat pendidikan, status perkawinan, lamanya hemodialisa, frekuensi hemodialisa, mengalami fatique, tingkat fatique sebelum dan setelah intervensi.

b. Distribusi responden berdasarkan Jenis Kelamin

\section{Tabel 2}

Distribusi Responden Berdasarkan Jenis Kelamin

\begin{tabular}{ccc}
\hline Jenis Kelamin & Jumlah & Persentasi \\
\hline Laki-laki & 7 & 43,8 \\
Perempuan & 9 & 56,3 \\
\hline Total & 16 & 100
\end{tabular}

Berdasrkan tabel diatas jumlah laki-laki yang menjalani hemodialisa sebanyak 7 orang $(43,8 \%)$, dan perempuan sebanyak 9 orang $(56,3 \%)$.

\section{c. Distribusi responden berdasarkan Usia}

\section{Tabel 3}

Distribusi Responden Berdasarkan Usia

\begin{tabular}{ccc}
\hline Usia & Jumlah & Persentasi \\
\hline 20-30 tahun & 3 & 18,8 \\
$>30$ & 13 & 81,3 \\
\hline Total & 16 & 100 \\
\hline
\end{tabular}

Karakterisitik responden berdasarkan usia yang menjalani hemodialisa yaitu usia 20-30 sebanyak 3 orang (18,8\%), dan usia $>30$ sebanyak 13 orang $(81,3 \%)$. 


\section{d. Distribusi responden berdasarkan Pekerjaan}

Tabel 4

Distribusi responden berdasarkan Pekerjaan

\begin{tabular}{lll}
\hline Pekerjaan & Jumlah & Persentasi \\
\hline IRT & 6 & 37,5 \\
Swasta & 9 & 56,3 \\
PNS & 1 & 6,3 \\
\hline Total & 16 & 100 \\
\hline
\end{tabular}

Berdasarkan tabel di atas dapat di lihat bahwa karakteristik responden berdasarkan pekerjaan yaitu IRT dengan jumlah responden 6 (enam) orang atau sebanyak 3,5\%, swasta 9 (sembilan) orang atau sebanyak 56,3\% dan PNS 1 (satu) orang atau sebanyak 6,3\%. Dengan demikian karakteristik responden berdasarkan pekerjaan terbanyak yaitu swasta

e. Distribusi responden berdasarkan Pendidikan

Tabel 5

Distribusi responden berdasarkan Pendidikan

\begin{tabular}{ccc}
\hline Pendidikan & Jumlah & Persentase \\
\hline Tidak sekolah & 2 & 12,5 \\
SD & 3 & 18,8 \\
SMP & 4 & 25 \\
SMA & 5 & 31,3 \\
PT & 2 & 12,5 \\
\hline Total & $\mathbf{1 6}$ & $\mathbf{1 0 0}$ \\
\hline
\end{tabular}

Berdasarkan tabel di atas dapat terlihat bahwa karakteristik responden berdasarkan tingkat pendidikan adalah responden yang tidak sekolah sebanyak 2 (dua) atau sebanyak 12,5\%, berpendidikan SD berjumlah 3 (tiga) orang atau sebanyak $18,8 \%$ dan responden yang berpendidikan SMP berjumlah 4 (empat) orang atau sebanyak 25\% serta responden yang berpndidikan perguruan tinggi sebanyak 2 (dua) orang atau sebanyak 12,5\%. Dengan demikian dapat diketahui bahwa sebagian besar responden berpendidikan SMP.

\section{f. Distribusi Responden Berdasarkan Status Perkawinan}

\section{Tabel 6}

Distribusi Responden Berdasarkan Status Perkawinan

\begin{tabular}{ccc}
\hline $\begin{array}{c}\text { Status } \\
\text { Perkawinan }\end{array}$ & Jumlah & Persentasi \\
\hline Lajang & 2 & 12,5 \\
Menikah & 10 & 62,5 \\
Duda & 1 & 6,3 \\
Janda & 3 & 18,8 \\
\hline Total & 16 & 100 \\
\hline
\end{tabular}

Berdasarkan tabel di atas dapat terlihat bahwa karakteristik responden berdasarkan status perkawinan adalah responden yang lajang berjumlah 2 
(dua) orang atau sebanyak $12,5 \%$ dan responden yang menikah berjumlah 10 orang atau sebanyak 62,5\%, responden yang duda sebanyak 1 (satu) orang atau sebanyak 6,3\%, serta yang janda berjumlah 3 atau sebanyak 18,8\%. Dengan demikian dapat diketahui bahwa sebagian besar responden berstatus menikah.

g. Distribusi Responden Berdasarkan Lamanya Hemodialisa

\section{Tabel 7}

Distribusi Responden Berdasarkan Lamanya Hemodialisa

\begin{tabular}{ccc}
\hline Lama Hemodialisa & Jumlah & Presentasi \\
\hline$<1$ tahun & 5 & 31,3 \\
$>1$ tahun & 2 & 12,5 \\
$>2$ tahun & 4 & 25 \\
$>3$ tahun & 5 & 31,3 \\
\hline Total & 16 & 100 \\
\hline
\end{tabular}

Berdasarkan tabel di atas dapat terlihat bahwa karakteristik responden berdasarkan lamanya hemodialisa adalah responden yang $<1$ tahun berjumlah 5 (lima) orang atau sebanyak 31,3\% dan responden yang $>1$ tahun berjumlah 2 orang atau sebanyak 12,5\%, responden yang $>2$ tahun sebanyak 4 orang atau sebanyak $25 \%$, serta yang $>3$ tahun berjumlah 5 atau sebanyak $31,3 \%$. Dengan demikian dapat diketahui bahwa sebagian besar responden berdasarkan lama hemodialisa adalah $<1$ tahun dan $>3$ tahun.

h. Distribusi Responden Berdasarkan Status Frekuensi Hemodialisa

\section{Tabel 8}

Distribusi Responden Berdasarkan Frekuensi Hemodialisa

\begin{tabular}{ccc}
\hline $\begin{array}{c}\text { Frekuensi } \\
\text { Hemodialisa }\end{array}$ & Jumlah & Persentasi \\
\hline 2 kali seminggu & 15 & 93,8 \\
3 kali seminggu & 1 & 6,3 \\
\hline Total & 16 & 100 \\
\hline
\end{tabular}

Berdasarkan tabel di atas dapat terlihat bahwa karakteristik responden berdasarkan frekuensi hemodialisa adalah responden yang $2 \mathrm{x}$ seminggu berjumlah 15 orang atau sebanyak $93,8 \%$ dan responden yang $3 x$ seminggu berjumlah 1 orang atau sebanyak 6,3\%. Dengan demikian dapat diketahui bahwa sebagian besar responden berdasarkan frekuensi hemodialisa adalah 2 kali seminggu.

i. Distribusi Responden Berdasarkan Mengalami Fatigue

Tabel 9

Distribusi Responden Berdasarkan Mengalami Fatigue

\begin{tabular}{ccc}
\hline $\begin{array}{c}\text { Mengalami } \\
\text { Fatigue }\end{array}$ & Jumlah & Persentase \\
\hline Ya & 16 & 100 \\
\hline Total & 16 & 100 \\
\hline
\end{tabular}


Berdasarkan tabel di atas dapat terlihat bahwa karakteristik responden berdasarkan yang mengalami fatigue sebanyak 16 orang atau sebanyak $100 \%$.

j. Distribusi responden berdasarkan Tingkat Fatique Sebelum Intervensi

Tabel 10

Distribusi responden berdasarkan Tingkat Fatique Sebelum Intervensi

\begin{tabular}{ccc}
\hline $\begin{array}{c}\text { Tingkat Fatique } \\
\text { Sebelum Intervensi }\end{array}$ & Jumlah & Persentasi \\
\hline Ringan & 2 & 12,5 \\
Sedang & 5 & 31,3 \\
Berat & 9 & 56,3 \\
\hline Total & 16 & 100 \\
\hline
\end{tabular}

Berdasarkan tabel di atas dapat terlihat bahwa distribusi responden berdasarkan tingkat fatique sebelum intervensi adalah ringan 2 orang sebanyak $12,5 \%$, sedang berjumlah 5 orang sebanyak $31,3 \%$ dan berat berjumlah 9 sebanyak 56,3\% . Dengan demikian dapat diketahui bahwa sebagian besar responden berdasarkan tingkat fatique sebelum intervensi adalah berat.

k. Distribusi responden berdasarkan Tingkat Fatique Sesudah Intervensi

Tabel 11

Distribusi responden berdasarkan Tingkat Fatique Sesudah Intervensi

\begin{tabular}{ccc}
\hline $\begin{array}{c}\text { Tingkat Fatique } \\
\text { Setelah Intervensi }\end{array}$ & Jumlah & Persentasi \\
\hline Ringan & 10 & 62,5 \\
Sedang & 6 & 37,5 \\
\hline Total & 16 & 100 \\
\hline
\end{tabular}

Berdasarkan tabel di atas dapat terlihat bahwa distribusi responden berdasarkan tingkat fatique sesudah dilakukan intervensi adalah ringan 10 orang sebanyak $62,5 \%$, sedang berjumlah 6 orang sebanyak 37,5\%. Dengan demikian dapat diketahui bahwa sebagian besar responden berdasarkan tingkat fatique setelah intervensi adalah ringan. 


\title{
2. Analisis Bivariat
}

\author{
Tabel 12
}

Distribusi Rata-rata Tingkat Fatique Berdasarkan Sebelum dan Sesudah Intervensi di Ruang Hemodialisa RS Islam Sukapura Tahun 2018

\begin{tabular}{cccccc}
\hline Variabel & Mean & SD & SE & $\begin{array}{c}\text { P } \\
\text { Value }\end{array}$ & N \\
\hline Tingkat & & & & & \\
Fatique & & & & & \\
Sebelum & 2,47 & 0,743 & 0,192 & 0,000 & 16 \\
$\begin{array}{c}\text { Intervensi } \\
\text { Setelah } \\
\text { Intervensi }\end{array}$ & 1,40 & 0,507 & 0,131 & & \\
\hline
\end{tabular}

Berdasarkan tabel diatas rata-rata tingkat fatique sebelum intervensi adalah 2,47 dengan standar deviasi 0,743 . Pada pengukuran kedua didapat rata-rata tingkat fatique setelah intervensi adalah 1,40 dengan standar deviasi 0,507. Terlihat nilai mean perbedaan antara pengukuran sebelum dan setelah intervensi adalah 1,07. Hasil uji statistik didapatkan nilai 0,000 maka dapat disimpulkan ada perbedaan signifikan antara tingkat fatique sebelum dan setelah intervensi.

\section{B. Pembahasan}

\section{Karakteristik responden}

Karakteristik responden pada penelitian ini meliputi jenis kelamin, usia, pekerjaan, tingkat pendidikan, status perkawinan, lamanya hemodialisa, frekuensi hemodialisa, mengalami fatique, tingkat fatique sebelum dan setelah intervensi. Berdasarkan hasil penelitian yang diperoleh jumlah responden wanita $56,3 \%$ lebih banyak dibanding laki-laki. Usia responden yang menjalani hemodialisa $81,3 \%$ terjadi pada usia $>30$ tahun. Pekerjaan responden 56,3\% adalah swasta. Tingkat pendidikan responden $31,3 \%$ adalah SMA. Status perkawinan responden $62,5 \%$ adalah menikah. Lamanya hemodialisa responden $31,3 \%$ adalah $>3$ tahun. Frekuensi hemodialisa responden 93,8\% adalah 2kali seminggu. Responden yang mengalami kelelahan/fatique akibat proses hemodialisa adalah $100 \%$. Tingkat fatique responden sebelum intervensi $56,3 \%$ adalah tingkat berat. Tingkat fatique responden setelah intervensi $56,3 \%$ adalah tingkat ringan.

2. Pengaruh Breathing Exercise terhadap Tingkat fatigue pada Pasien Hemodialisa di RS Islam Sukapura

Berdasarkan hasil penelitian dengan uji $\mathrm{T}$ didapatkan rata-rata tingkat fatique sebelum intervensi adalah 2,47 dengan standar deviasi 0,743. Pada pengukuran kedua didapat rata-rata tingkat fatique setelah intervensi adalah 1,40 dengan standar deviasi 0,507 . Terlihat nilai mean perbedaan antara pengukuran sebelum dan setelah intervensi adalah 1,07. Hasil uji statistik didapatkan nilai 
0,000 maka dapat disimpulkan ada perbedaan signifikan antara tingkat fatique sebelum dan setelah intervensi.

Hasil penelitian sesuai dengan penelitian yang dilakukan oleh (Ghanbari, Shirmohamadi, Paryad, Bazghale, \& Mohammadpourhodki, 2018) ada perbedaan yang signifikan $(\mathrm{P}=0,0001)$ pada kelompok eksperimen sebelum dan sesudah intervensi mengenai mean dan standar deviasi serta perubahan skor ratarata dimensi fatigue kecuali fatigue mental yang membandingkan perubahan rata-rata dalam skor total fatigue dalam hal latihan pernapasan, dapat dilihat bahwa ada perbedaan statistik yang signifikan dan terbalik antara (melakukan) latihan pernapasan dan perubahan dalam skor total fatigue, yaitu lebih banyak latihan pernapasan yang digunakan, semakin rendah skor keletihannya. Ada peningkatan statistik yang signifikan dalam skor rata-rata dimensi fatigue setelah latihan pernapasan, fatigue umum ( $\mathrm{p}=0,0001)$, fatigue fisik $(\mathrm{p}=0,0001)$, mengurangi aktivitas $(\mathrm{p}=0,0001)$ dan mengurangi motivasi $(\mathrm{p}=0,0001)$, tetapi ada tidak ada perbedaan signifikan dalam fatigue mental. Prediktor perubahan total skor fatigue, latihan pernapasan $(\mathrm{p}<0,0001)$ dan semprotan Salbutamol ( $\mathrm{p}$ $<0,013$ ) dianggap sebagai dua faktor yang mempengaruhi perubahan skor fatigue dalam beberapa analisis.

Hasil penelitian sesuai dengan yang dilakukan (Afiyanti, Achmad, \& Sangkala, 2018), menemukan penurunan yang signifikan $(\mathrm{P}<0,01)$ dalam skor fatigue rata-rata kedua kelompok. Melakukan RBE empat kali sehari secara efektif mengurangi fatigue lebih baik daripada RBE dua kali sehari pasien kanker ginekologi menjalani kemoterapi.

Hasil penelitian sesuai juga yang dikemukakan oleh Masoumeh Zakerimoghadam, dkk, 2011 bahwa keparahan fatigue rata-rata sebelumnya (55.766) dan setelah (40.166) menggunakan latihan pernapasan di kelompok pengalaman $(\mathrm{p}=0 \%)$ berbeda secara signifikan. Sementara dalam kelompok kontrol $(\mathrm{p}=0,002)$ sebelumnya $(54,166)$ dan sesudahnya (52.200) studi memiliki sedikit perbedaan. Ada korelasi invers yang signifikan antara menggunakan pernapasan latihan dan keparahan fatigue $(r=-0,593, p=0,001)$. Berarti intensitas fatigue untuk pengalaman dan kelompok kontrol menurun menjadi $40.916 \pm 14.4$ dan $52.20 \pm 8.539$ setelah penelitian, masing-masing $(\mathrm{p}=$ 0,001). Ada perbedaan yang signifikan dalam keparahan fatigue antara pengalaman dan kelompok kontrol setelah penelitian.

\section{Kesimpulan}

Berdasarkan hasil pengukuran tingkat fatique sebelum intervensi adalah ringan 2 orang sebanyak $12,5 \%$, sedang berjumlah 5 orang sebanyak $31,3 \%$ dan berat berjumlah 9 seanyak 56,3\%. Dengan demikian dapat diketahui bahwa sebagian besar responden berdasarkan tingkat fatique sebelum intervensi adalah berat.

Berdasarkan hasil pengukuran tingkat fatique setelah intervensi adalah ringan 10 orang sebanyak $62,5 \%$, sedang berjumlah 6 orang sebanyak $37,5 \%$. Dengan demikian 
dapat diketahui bahwa sebagian besar responden berdasarkan tingkat fatique setelah intervensi adalah ringan.

Berdasarkan hasil penelitian dengan uji $\mathrm{T}$ didapatkan rata-rata tingkat fatique sebelum intervensi adalah 2,47 dengan standar deviasi 0,743. Pada pengukuran kedua didapat rata-rata tingkat fatique setelah intervensi adalah 1,40 dengan standar deviasi 0,507. Terlihat nilai mean perbedaan antara pengukuran sebelum dan setelah intervensi adalah 1,07. Hasil uji statistik didapatkan nilai 0,000 maka dapat disimpulkan ada perbedaan signifikan antara tingkat fatique sebelum dan setelah intervensi. Berarti ada pengaruh Breathing Exercise terhadap tingkat fatique pada pasien hemodialisa di RS Islam Sukapura Jakarta tahun 2019

\section{BIBLIOGRAFI}

Afiyanti, Yati, Achmad, Engkus Kusdinar, \& Sangkala, Moh Syafar. (2018). Effectiveness of Relaxation Breathing Exercise on fatigue in gynecological cancer patients undergoing chemotherapy. International Journal of Nursing Sciences, 5(4), 331-335.

Ghanbari, Atefeh, Shirmohamadi, Nasim, Paryad, Ezzat, Bazghale, Milad, \& Mohammadpourhodki, Reza. (2018). Effect of Breathing Exercises on Fatigue Dimensions in Patients with COPD. Medical Science and Discovery, 5(4), 174179.

Hasmi, Clarissa Hasana. (2017). Hubungan Aktivitas Fisik dengan Fungsi Kognitif pada Pasien Hemodialisis Kronik. Universitas Sumatera Utara.

Indonesia, Kementerian Kesehatan Republik. (2018). Cegah dan Kendalikan Penyakit Ginjal dengan CERDIK dan PATUH. Retrieved January 3, 2021, from Kemenkes.co.id website: https://www.kemkes.go.id/article/view/18030700007/cegah-dan-kendalikanpenyakit-ginjal-dengan-cerdik-dan-patuh.html

Jhamb, Manisha, Weisbord, Steven D., Steel, Jennifer L., \& Unruh, Mark. (2008). Fatigue in patients receiving maintenance dialysis: a review of definitions, measures, and contributing factors. American Journal of Kidney Diseases, 52(2), $353-365$.

Kompasiana. (2018). Penyakit Ginjal Kronis Jangan Anggap Remeh, Segera Periksa Ke Dokter. Retrieved January 3, 2021, from Kompasiana.com website: https://www.kompasiana.com/penaulum/5aa12539ab12ae5fc03b2762/setiap-8maret-ditetapkan-sebagai-hari-ginjal-sedunia

Kusniawati, Kusniawati. (2018). Hubungan Kepatuhan Menjalani Hemodialisis Dan Dukungan Keluarga Dengan Kualitas Hidup Pasien Gagal Ginjal Kronik Di Ruang Hemodialisa Rumah Sakit Umum Kabupaten Tangerang. Jurnal Medikes (Media 
Maesaroh

Informasi Kesehatan), 5(2), 206-233.

Manurung, Rostinah, \& Sari, Juli Yana. (2020). Hubungan Dukungan Keluarga Dengan Kepatuhan Diet Pada Pasien Gagal Ginjal Kronik Di Rumah Sakitumum Imelda Pekerja Indonesia (RSU IPI) Medan Tahun 2019. Jurnal Ilmiah Keperawatan Imelda, 6(1), 27-35.

Notoatmodjo, Soekidjo. (2012). Metodologi penelitian kesehatan. Jakarta: Rineka Cipta

Parvan, Kobra, Jabar-Zadeh, Farank, Sarbakhsh, Parvin, Akhtari-Shojai, Ebrahim, \& Zarei, Tahereh. (2017). The effect of exercise during hemodialysis on fatigue and self-efficacy in patients: a blind randomized clinical trial. Journal of Clinical and Analytical Medicine, 1, 491.

Tuloli, Teti Sutriyati, Madania, Moh Adam Mustapa, \& Tuli, Evania P. (2019). Evaluasi Penggunaan Obat Pada Pasien Gagal Ginjal Kronik Yang Menjalani Hemodialisis Di Rsud Toto Kabila Periode 2017-2018. Parapemikir: Jurnal Ilmiah Farmasi, $8(2), 25-32$.

Utami, N. I. A. Puspita. (2019). Tugas Akhir Nersdeskripsi Kasus: Penerapan Intradialytic Range Of Motion Exercise Untuk Menurunkan Tekanan Darah Pada Pasien Av Fistula Yangmenjalani Hemodialisis. 